Audiology

Neurotology
Audiol Neurotol 2020;25:25-34

DOI: $10.1159 / 000502712$
Received: May 3, 2019

Accepted after revision: August 13, 2019

Published online: September 25, 2019

\title{
Concepts and Physiological Aspects of the Otolith Organ in Relation to Electrical Stimulation
}

\author{
Ian S. Curthoys \\ Vestibular Research Laboratory, School of Psychology, University of Sydney, Sydney, NSW, Australia
}

\section{Keywords}

Vestibular labyrinth - Balance - Galvanic stimulation - Utricle . Saccule

\begin{abstract}
Background: This paper discusses some of the concepts and major physiological issues in developing a means of electrically stimulating the otolithic system, with the final goal being the electrical stimulation of the otoliths in human patients. It contrasts the challenges of electrical stimulation of the otolith organs as compared to stimulation of the semicircular canals. Electrical stimulation may consist of trains of short-duration pulses (e.g., $0.1 \mathrm{~ms}$ duration at $400 \mathrm{~Hz}$ ) by selective electrodes on otolith maculae or otolithic afferents, or unselective maintained DC stimulation by large surface electrodes on the mastoids - surface galvanic stimulation. Summary: Recent anatomical and physiological results are summarized in order to introduce some of the unique issues in electrical stimulation of the otoliths. The first challenge is that each otolithic macula contains receptors with opposite polarization (opposing preferred directions of stimulation), unlike the uniform polarization of receptors in each semicircular canal crista. The puzzle is that in response to the one linear acceleration in the one macula, some otolithic afferents have an increased activation whereas others have de-
\end{abstract}

creased activation. Key Messages: At the vestibular nucleus this opposite receptor hair cell polarization and consequent opposite afferent input allow enhanced response to the one linear acceleration, via a "push-pull" neural mechanism in a manner analogous to the enhancement of semicircular canal responses to angular acceleration. Within each otolithic macula there is not just one uniform otolithic neural input to the brain - there are very distinctly different channels of otolithic neural inputs transferring the neural data to the brainstem. As a simplification these channels are characterized as the sustained and transient systems. Afferents in each system have different responses to stimulus onset and maintained stimulation and likely different projections, and most importantly different thresholds for activation by electrical stimulation and different adaptation rates to maintained stimulation. The implications of these differences are considered.

(c) 2019 S. Karger AG, Basel

\section{Introduction}

Natural Stimulation of the Otoliths

Head movements consist of angular and linear accelerations which activate different regions of the vestibular system - angular accelerations stimulate mainly the

\section{KARGER}

(c) 2019 S. Karger AG, Basel

E-Mail karger@karger.com

www.karger.com/aud
Ian S. Curthoys

School of Psychology

Brennan MacCallum Building, A18, University of Sydney

Sydney, NSW 2006 (Australia)

E-Mail ian.curthoys@sydney.edu.au 
Table 1. Numbers of otolithic afferents from the utricular and saccular maculae in the human labyrinth

\begin{tabular}{llll}
\hline & $\begin{array}{l}\text { Lopez et al., } \\
2005\end{array}$ & $\begin{array}{l}\text { Bergström, } \\
1973\end{array}$ & $\begin{array}{l}\text { Lee et al., } \\
1990\end{array}$ \\
\hline Utricular afferents & 3,023 & 2,885 & 4,839 \\
Saccular afferents & & 2,589 & 3,744 \\
Total otolithic afferents & 5,474 & 8,583 \\
\hline
\end{tabular}

canals, linear accelerations stimulate the otoliths. Because the otoliths are not on the axis of head rotation but offset from it, every head movement contains both angular and linear acceleration components, so both canals and otoliths are stimulated by any head movement. The otoliths do not function in isolation, but instead otolithic neural signals are integrated with canal neural signals at the vestibular nucleus of the brainstem, and this phenomenon is termed convergence. The responses to natural (or electrical) otolithic stimulation consist of eye movements, postural changes, and sensations. The small myogenic potentials to sound or vibration (vestibular evoked myogenic potentials, VEMPs) are now a frequently measured otolithic response used in clinical testing [see for reviews, Curthoys et al., 2018; Rosengren and Colebatch, 2018]. Both the utricular maculae and the saccular maculae have vestibulospinal and oculomotor projections, but selective electrical stimulation of the otoliths in animals has confirmed that the utricular macula has stronger projections to the oculomotor system than the saccular macula [Curthoys, 2010; Uchino and Kushiro, 2011]. The numbers of utricular and saccular afferents are shown in Table 1, with the big variability reflecting the many factors (such as age, methodology, etc.) affecting the numbers.

The overall anatomy of the otolithic maculae in humans and guinea pigs is similar. The utricular and saccular maculae are sheets of receptor cells with the hair bundles of the receptors usually projecting into the otolithic membrane on which are the otoconia. Each receptor is morphologically polarized to optimally detect a linear acceleration in one direction [Flock, 1964; Lindeman, 1969] (Fig. 1b). Specifically the polarization refers to the fact that for each receptor hair cell, linear acceleration causes deflections of the stereocilia toward the distinct longest cilium (the kinocilium [k in Fig. 1a]) and results in excitatory membrane potential changes, whereas deflections in the opposite direction cause inhibitory membrane potential changes. There are 2 different types of receptors, amphora-shaped type I (Fig. 1a) and barrel-shaped type II receptors innervated by afferents with different endings. The afferent endings on type I receptors envelop the receptor and are called calyx endings. It is the unique calyx ending which likely endows the irregular afferents with very high precision of their high-frequency response [Curthoys et al., 2019b]. The endings on type II receptors are small bouton endings. The afferent fibers from the maculae show very different classes of response - some have highly regular resting discharge whereas others, from type I receptors at the specialized region called the striola (Fig. 1b, c), have irregular resting discharge. The overall result is that each otolith macula is a complex highly specialized receptor structure. Table 1 gives the total numbers of otolithic afferents from each macula in the human labyrinth.

Individual receptors prefer linear accelerations in a particular direction, but there is a systematic ordered change in the preferred direction of receptor cells around the macula (Fig. 1b, c). Receptors on either side of an imaginary line - called the line of polarity reversal (the LPR) - have opposite preferred directions of stimulation. The band around the LPR is called the striola, and receptors in this striolar region have short stiff hair bundles with tenuous attachment to the otolithic membrane [Curthoys et al., 2019b], and afferents from this region have irregular resting discharge and (as is explained below), constitute the transient system.

In terms of response to stimulation, a natural linear acceleration stimulus in a particular direction (Fig. 1a, b) will activate receptors with that preferred direction but will act to silence the receptors with the opposite directional preference (i.e., on the opposite side of the LPR). The result is that the one linear acceleration stimulus causes an increase in firing of one set of afferents and simultaneously causes a decrease in activity of the afferents from receptors on the opposite side of the LPR. In the labyrinth on the other side of the head, this anatomical organization and physiological response pattern is mirrored (Fig. 1b, c). As is explained below, Uchino and Kushiro have shown how this pattern of simultaneous excitation and inhibition on each macula from a single linear acceleration can act to enhance the sensitivity of the response by means of an otolithic "push-pull" neural interaction at the vestibular nuclei [Uchino and Kushiro, 2011], an interaction analogous to the pushpull interaction of bilateral semicircular canal afferents at the vestibular nucleus [Precht and Shimazu, 1965; Markham et al., 1977]. This matter is considered in detail below. 


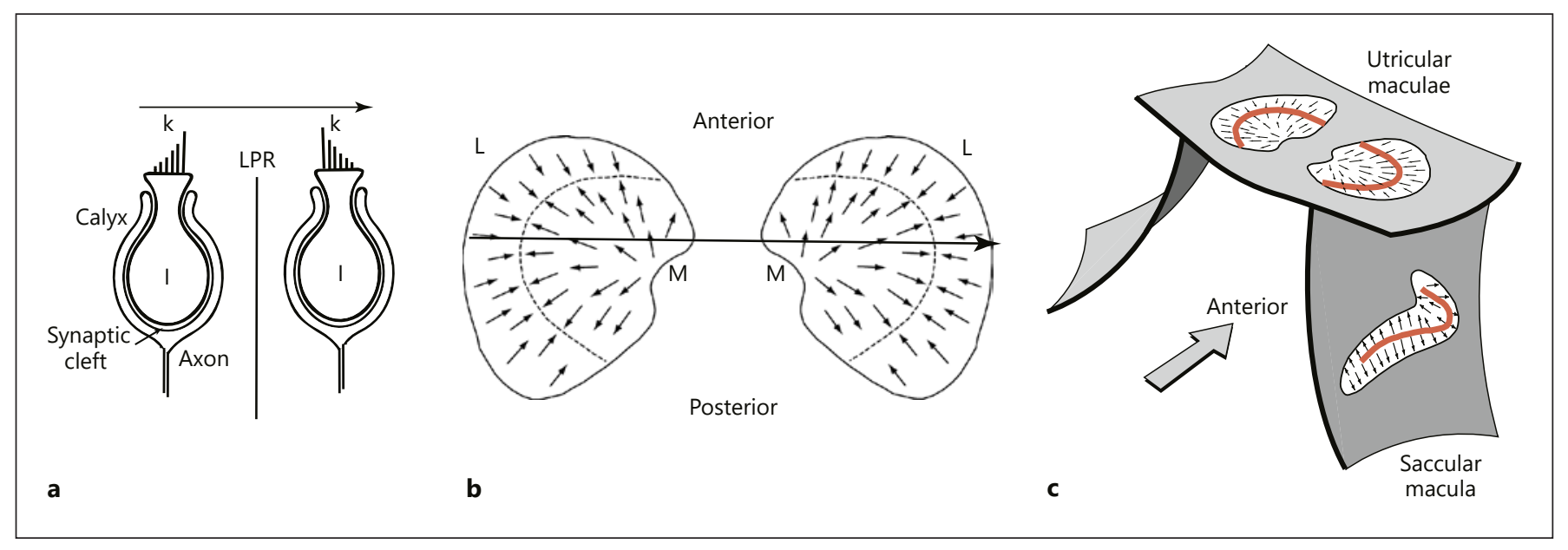

Fig. 1. Simplified schematics of the type I receptors, the line of polarity reversal (LPR) and the spatial organization of the utricular and saccular maculae. a Two type I receptors on either side of the LPR. The afferent fiber forms a calyx ending which envelops the whole receptor. The kinocilium is the longest cilium and is identified by the letter $\mathrm{k}$ in this schematic. A linear acceleration directed from left to right will activate the left-side type I receptor because the cilia will be deflected towards the kinocilium, but simultaneously inhibit the right-side receptor whose cilia will be deflected away from the kinocilium. b View looking straight down on sche- matic representations of the 2 utricular maculae during laterally directed linear acceleration to the right (shown by the large arrow). The small arrows represent the preferred directions of each receptor, and the systematic change in preferred direction and the opposite polarization on either side of the LPR (dashed line) are shown. The 2 maculae are mirror images of one another. The medial sectors are identified by the letter $M$ and the lateral sectors by the letter L. c The approximate spatial configuration of the utricular and saccular maculae. The band around the LPR is called the striola.
Suzuki et al. [1969] electrically stimulated the nerve from the utricular macula in cats and observed the resulting oculomotor responses. After removing the ampulla of the horizontal canal, Fluur and Mellström [1970a, b] electrically stimulated the surface of the otolithic maculae in cats and observed the direction of the oculomotor response. At that time the methods for the exact measurement of 3-dimensional eye movement were not accessible [Fluur and Mellström, 1970b]. Curthoys [1987] followed the lead of Fluur and Mellström in using direct visual observation in response to electrical stimulation of guinea pig maculae but managed to do so with the horizontal canal ampulla intact. Curthoys reported eye movement directions different from those reported by Fluur and Mellström, but the results were very limited because of the direct visual observation of the initial direction of the oculomotor response and the confound of canal ablation by Fluur and Mellström. Goto and colleagues confirmed the major effects of utricular and saccular stimulation in cats [Curthoys, 1987; Goto et al., 2003, 2004]. As discussed below, issues encountered in these studies are relevant to the question of the electrical stimulation of the human otolith organs.

\section{The Neural Responses: Sustained versus Transient}

Recordings of single primary otolithic afferents in the frog (and confirmed since in mammals, birds, fish) have shown that primary otolithic afferents with regular resting discharge respond to tilts and low-frequency linear acceleration stimulation (the sustained system), but these neurons have poor or absent response to high frequencies of linear acceleration (vibration). In contrast other primary otolithic neurons with irregular resting discharge respond with great sensitivity to high-frequency vibration but have poor response to maintained stimulation (the transient system) [Curthoys et al., 2017, 2019b]. Their preferred stimulus is vibration which consists of many changes in linear acceleration (which are referred to as jerks), and these jerk-sensitive transient neurons have very poor response to low-frequency linear acceleration stimulation [Curthoys et al., 2017, 2019b]. On the other hand, the tilt-sensitive regular afferents do not respond to high-frequency vibration. The sustained and transient distinction applies to both utricular and saccular afferents. These distinctly different response characteristics are linked to the regularity of the afferent's resting discharge rate (Table 2). Afferents with regular resting 
Table 2. Summary of the major features of the sustained and transient otolithic afferent systems

\begin{tabular}{|c|c|c|}
\hline & Sustained & Transient \\
\hline 1. Stimulus frequency & low frequency (maintained tilt) & high frequency (vibration) \\
\hline 3. Threshold for galvanic stimulation & higher than regulars & low threshold \\
\hline 5. Phase locking precision & no & very high precision \\
\hline 6. Average resting rate & high & low \\
\hline 7. Conduction velocity & slow & fast \\
\hline 10. Regularity of resting discharge & regular & irregular \\
\hline Simplified response characterization & gravity and maintained tilt detection & $\begin{array}{l}\text { jerk detection - onset of linear } \\
\text { acceleration }\end{array}$ \\
\hline
\end{tabular}

The evidence justifying each of these statements (rows) can be found in the following references: 1 . frequency response [Fernandez and Goldberg, 1976a; Curthoys et al., 2019a]; 2. adaptation [Goldberg et al., 1984]; 3. galvanic threshold [Goldberg et al., 1984; Kim and Curthoys, 2004]; 4. phase locking [Curthoys et al., 2019a]; 5. phase locking precision [Curthoys et al., 2019a]; 6. resting rate [Curthoys et al., 2016]; 7. conduction velocity [Yagi et al., 1977; Fernàndez et al., 1990]; 8. axon diameter [Goldberg and Fernàndez, 1977]; 9. location of origin [Fernàndez et al., 1990; Curthoys et al., 2012]; 10. regularity [Fernàndez and Goldberg, 1976b; Zhu et al., 2011; Curthoys et al., 2012]; see also Goldberg [2000, 2012].

discharge respond well to maintained stimulation but have poor or absent responses to high-frequency stimulation such as that produced by sound and vibration. On the other hand, afferents with irregular resting discharge have poor response to maintained stimuli but strong response to sound or vibration with a very high precision of phase locking of action potentials to particular phase bands of the BCV or ACS waveform [Curthoys et al., 2019a, b].

The high temporal precision of irregular afferents has been interpreted as showing that these irregular otolithic afferents are highly responsive to changes in linear acceleration (jerk), such as at the onset of a movement, rather than maintained linear acceleration. They show relatively rapid adaptation to maintained stimulation - either acceleration or electrical stimulation [Goldberg et al., 1984]. Irregular afferents tend to originate from the striola region of the macula and contact type I receptors [Goldberg et al., 1990; Curthoys et al., 2012, 2016]. The high sensitivity for vibration of irregular afferents has evolutionary roots in the responses of fish otolithic receptors and afferents, detecting the direction of vibration (particle motion) of predators or the location of calls of the opposite gender [Popper and Fay, 2011; Zeddies et al., 2012]. These very different stimulus preferences of the sustained and transient systems are preserved centrally [Curthoys et al., 2017].

Table 2 summarizes the different characteristics of the sustained and transient systems. Large diameter fibers with fast conduction times have irregular resting discharge and so constitute the transient system, and it is these which have been shown to have a lower threshold for activation by electrical stimulation.

How does this sustained-transient distinction relate to the oculomotor and postural responses to otolithic stimulation? Measuring the maintained ocular torsion response to maintained head tilt stimulation tests the sustained otolithic system, whereas measuring responses to sound and vibration (such as VEMPs) tests the jerk sensitive transient system, because sound and vibration do not 
activate the regular sustained afferents [Curthoys et al., 2006; Zhu et al., 2011].

These differences between transient and sustained systems have implications for the behavioral response to electrical stimulation, specifically that (1) brieflow-intensity currents will preferentially activate irregular afferents and (2) the responses to long duration maintained electrical stimuli will reflect mainly the activity of the sustained afferents, because of the adaptation of the irregular afferents. Otolithic transient responses are very fast - so for ocular VEMP responses to vibration the latency from stimulus onset to the onset of the response at the inferior oblique eye muscles is about $6 \mathrm{~ms}$ [Burgess et al., 2013]. That is the time to cross 3 synapses and travel the long distance from the macula to the inferior obliques. Recent evidence has shown that the irregular otolithic afferents of the transient system have phase locking to high-frequency $(>1,000 \mathrm{~Hz})$ air-conducted sound and bone-conducted vibration, which implies that every individual cycle of the sinusoidal stimulus is effective in activating the receptor/afferent. The temporal precision of this phase locking of these irregular afferents is higher than for phase locking of auditory afferents to sound [Curthoys et al., 2019a]. A recent review explores these matters [Curthoys et al., 2019b].

\section{Implications of Anatomical Structure and Physiology}

\section{"Push-Pull" Otolithic Organization}

One of the major features of the semicircular canal afferent neural system is how the horizontal canals in each labyrinth function as a push-pull system - the one horizontal angular acceleration activates the afferents from the horizontal semicircular canal in one labyrinth (the "push") and simultaneously inhibits the afferents from the semicircular canal in the opposite labyrinth (the "pull"). Central interaction at the vestibular nuclei in the brainstem causes that contralateral inhibition to enhance the sensitivity of the neural response to angular acceleration [Precht and Shimazu, 1965; Markham et al., 1977], but at rest these mutual inhibitory interactions are in balance. Unilateral vestibular loss results in major disruption of that balance causing spontaneous nystagmus and asymmetric responses to angular acceleration [Halmagyi et al., 2017]. In the otoliths it appears that a similar "pushpull” principle operates [Uchino and Kushiro, 2011].

Uchino has identified 2 modes of inhibitory interaction in the otolithic system - commissural inhibition between the bilateral otolithic maculae and cross-striolar inhibition across the striola within a single macula [Uchino, 2004; Uchino and Kushiro, 2011]. Uchino reports that both types of inhibitory interaction operate in both the utricular and saccular systems, but that commissural inhibition is predominant for the utricular system and cross-striolar inhibitory interaction is predominant for the saccular system. Specifically in the utricular system, the commissural interaction is between the medial sectors in each labyrinth (marked as $\mathrm{M}$ in Fig. $1 \mathrm{~b}$ ) and between the lateral sectors in each labyrinth (marked as $\mathrm{L}$ in Fig. 1b). A linear acceleration will activate receptors in the medial sector in one labyrinth and simultaneously inhibit receptors in the medial sector in the contralateral labyrinth (Fig. 1b). The mutual inhibitory interaction between the 2 medial sectors acts to enhance sensitivity, just as it does for horizontal canal neurons. Similar commissural inhibitory interaction takes place between the 2 lateral utricular sectors, again enhancing sensitivity. The outcome of these interactions is the characteristic sensitive oculomotor and postural responses to linear acceleration [Goldberg, 2012]. It appears that the lateral sectors project mainly to the cerebellum, whereas the medial sectors project mainly to the vestibular nuclei of the brainstem and so have a major role in the oculomotor responses [Maklad et al., 2010].

Bilateral biphasic galvanic vestibular stimulation (GVS) to the mastoids (cathode on one mastoid and anode on the other mastoid) duplicates the effects of a linear acceleration (the cathode activating all afferents in one labyrinth and simultaneously the anode inhibiting all afferents in the other labyrinth), resulting in postural and oculomotor responses mimicking the responses to linear acceleration [Watson et al., 1998; Kim, 2013]. Bilateral GVS and even unilateral GVS causes what is probably an otolith-dominated response - maintained ocular torsion [Kim, 2013; MacDougall et al., 2002]. It is most likely otolith-dominated because it is a maintained eye position response - canal-evoked responses generate eye velocity rather than eye position [Cohen et al., 1964]. For the otoliths, unilateral GVS stimulation is the partial analog of unilateral caloric stimulation.

With the head stationary, the neural output from the 2 utricular maculae will effectively be in a state of "neural equilibrium" akin to the neural equilibrium between the neural outputs from the 2 horizontal canals at rest [Curthoys et al., 1988; Halmagyi et al., 2017]. Removal of one labyrinth, or even just one utricular macula, will upset that equilibrium - the neurons from one utricular macula will have resting discharge, but there will be no inhibitory opposition from the other (absent) utricular macula. This 
will cause an imbalance between the neural activity of the 2 utricular macula neurons (analogous to that occurring in the horizontal canal system) which will cause roll head tilt, yaw head deviation and postural disturbances [Curthoys et al., 1988; De Waele et al., 1989]. These utricularinduced symptoms compensate over time (just as horizontal spontaneous nystagmus declines following a unilateral labyrinthectomy [Smith and Curthoys, 1989]), presumably as the balance in utricular neural activity between the 2 vestibular nuclei is restored. After vestibular compensation, tests of otolith function using sustained stimuli (e.g., ocular counterrolling to maintained head tilt) show little asymmetry [Otero-Millan et al., 2017], whereas tests using transient stimuli (ocular VEMPs) show the side of loss very clearly [Iwasaki et al., 2008].

In the saccular macula there is predominantly crossstriolar inhibition between the dorsal and ventral sectors (Fig. 1c) of each saccular macula. So, a vertical linear acceleration (such as gravity) will activate receptors in the ventral sector and inhibit receptors in the dorsal sector of that same saccular macula and so enhance the neural response to that vertical linear acceleration. In the case of the saccular macula, a bipolar biphasic galvanic stimulus to the mastoids will simultaneously activate afferents from both dorsal and ventral sectors of the saccular macula on the cathodal side and simultaneously inhibit the afferents from both dorsal and ventral sectors on the anodal side. The result would be cancellation of afferent input from both saccular maculae.

In contrast to the case with the utricular maculae, unilateral vestibular loss or specific ablation of the saccular macula would be expected to have little effect on oculomotor or postural behavior - both opposing sectors being removed simultaneously, with the saccular macula in the contralateral labyrinth remaining. This account explains the very different behavioral responses after unilateral utricular ablation with (in guinea pigs) - ipsilesional roll head tilt and yaw head tilt [Curthoys et al., 1988; De Waele et al., 1989] as opposed to saccular ablation where there is virtually no behavioral evidence of any postural or oculomotor disturbance, presumably because the 2 opposing (cross-striolar) sectors have both been removed.

Cross-striolar inhibitory interaction and the opposite receptor polarization across the LPR pose a unique problem for electrical stimulation of the otolithic maculae. Consider a gross monopolar stimulating electrode close to the utricular macula. Depending on its exact location, the one current pulse will simultaneously cause activation of oppositely polarized receptors and afferents on both sides of the LPR. This pattern of afferent neural activation sim- ply cannot occur with natural linear acceleration - the one natural linear acceleration cannot cause simultaneous activation of afferents on both sides of the LPR because the receptors have opposite preferred directions. Presumably the effect of this simultaneous activation of afferents from opposite sides of the LPR will be to act to cancel each other. In the guinea pig, at some electrode locations there can be a very long delay (seconds) after stimulus onset before an eye movement response, and this delay may be due to cross-striolar cancellation [Curthoys, 1987]. One possibility is that the response may eventually occur due to one set of afferents adapting and so progressively nullifying the cancellation and "releasing" the response. As noted above there is good evidence that irregular afferents adapt more rapidly to galvanic stimulation than regular afferents [Goldberg et al., 1984; Dlugaiczyk et al., 2019] and so the cancellation from irregular afferents would become ineffective and reveal a response to stimulation from the sustained regular afferent component. A consequence would be the appearance of a response to the electrical stimulation after a very long latency. This very unusual response pattern was observed by Curthoys in the 1987 guinea pig study [Curthoys, 1987] (and confirmed by Chow and colleagues in the chinchilla [Chow et al., 2018; Boutros et al., 2019; Hageman et al., 2019]) all of whom directly electrically stimulated the utricular macula.

\section{Convergence of Otolith and Canal Neural Input}

The idea that there are separate parallel neural paths for otolithic and for canal afferent information is true only to a limited extent. Some single neurons at the vestibular nuclei show responses only to angular acceleration or responses only to linear acceleration. Such "pure" otolith or "pure" canal neurons are uncommon in the vestibular nuclei [Curthoys and Markham, 1971; Dickman and Angelaki, 2002]. In the 1971 study we found only about $25 \%$ of vestibular nucleus neurons were pure horizontal canal neurons. So, a considerable proportion of single neurons in the vestibular nuclei can be activated either by canal or by otolith stimulation. They were termed convergent neurons and are reported to constitute about half of all vestibular nucleus neurons in primates [Dickman and Angelaki, 2002].

Self-generated movements almost always contain both angular and linear acceleration components and so both otoliths and canals are stimulated. The fact that centrally there is a great amount of convergence of afferents of individual primary canal neurons and individual primary
Audiol Neurotol 2020;25:25-34 DOI: $10.1159 / 000502712$
Curthoys 
otolithic neurons onto single central vestibular neurons implies a neuron receiving such convergent input cannot discriminate between canal and otolith input - it just receives action potentials and is activated by either the canal input or the otolith input or both. (Convergence in the vertical system is probably stronger than in the horizontal canal system [Hess and Dieringer, 1991]). Convergence means that a stimulating electrode on the horizontal canal nerve will activate both "pure" canal neurons and the convergent canal-otolith neurons at the vestibular nucleus and so have influence on otolith-related neural pathways and thus otolithic responses. In other words, the electrodes presently being used to stimulate human canal nerves are providing some stimulation of otolith dependent neurons. The behavioral evidence of such otolithcanal convergence is the strong modulation of canalinduced horizontal nystagmus in healthy subjects by simultaneous linear acceleration on a human centrifuge [Lansberg et al., 1965; Curthoys et al., 1992].

\section{The Surgical Approach}

How and where should the stimulating electrode be placed for selective stimulation of the otolithic system? This is a much more anatomically complex question than the placement of semicircular canal nerve-stimulating electrodes. It is only the upturned edge of the tobogganlike utricular macula (Fig. 2) which is attached to the temporal bone - this is the region where the afferent neurons leave the macula [Uzun-Coruhlu et al., 2007]. The remainder of the macula is supported on the membrana limitans [Hara and Kimura, 1993; Mukherjee et al., 2011, 2019]. The hair bundles of the receptor hair cells are on the dorsal surface of the utricular macula - projecting into the otolithic membrane on the dorsal surface of the otolithic membrane upon which are the otoconia. The utricular macula is close to and just dorsal to the footplate of the stapes [Mukherjee et al., 2011]. If the stimulating electrode is placed on the ventral side of the utricular macula, it will be in direct contact with the myelinated axons of the utricular afferents.

Surgery for electrode placement should endeavor to keep the endolymphatic compartments of the labyrinth intact, since breaching of these compartments likely results in labyrinthectomy. This means that placement of the stimulating electrodes on the surface of the macula is to be avoided since that requires breaching the wall of the membranous labyrinth. For that reason, the preferred location for utricular electrodes is the ventral surface of the

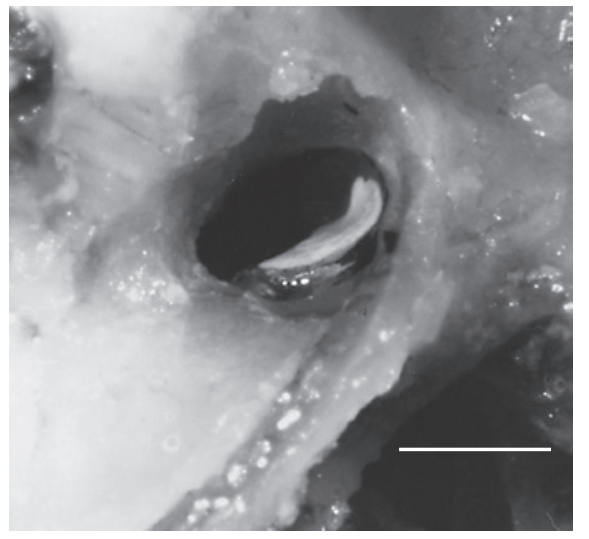

Fig. 2. A lateral view of a guinea pig utricular macula after the ampulla of the horizontal canal has been removed, to show the curved "toboggan-like" configuration of the utricular macula (guinea pig). The upturned region is attached to bone while the remainder floats on the membrana limitans and is not attached to bone [Mukherjee et al., 2019]. Scale bar, $1 \mathrm{~mm}$. Micro-CT scans of human utricular macula indicate it has a similar configuration, with the afferent fibers leaving the macula at the upturned region [Uzun-Coruhlu et al., 2007]. Figure reproduced with permission of the Aerospace Medical Association from Curthoys [1987].

utricular macula where it is in contact with the myelinated afferent nerve fibers from the macula [Pastras et al., 2018]. Placement of the electrodes in Scarpa's ganglion will have less risk of labyrinthectomy but such electrodes will unselectively activate afferents from many vestibular sense organs. So far, the question of location of the stimulating electrode for selective stimulation of the saccular macula has proved to be intractable. The proximity of the saccular macula to the cochlea suggests it is most likely stimulated by spread of current from cochlear implant activation, although the fact that an ocular VEMP (from utricular afferent activation) could be generated by a cochlear implant shows that current may spread even up to the distant utricular nerve [Parkes et al., 2017].

Selectivity is determined by the electrode placement and stimulation waveform. The most selective electrodes are bipolar electrodes [Curthoys, 1987; Uchino and Kushiro, 2011], although many studies have used monopolar electrodes. A crucial issue is the location of the reference electrode since its location will determine how selective stimulation will be because its location determines the current path activating the neurons [Handler et al., 2017; Glueckert et al., 2018; Schier et al., 2018]. In something as complex as the temporal bone, the current path is extremely complicated because of the large areas of poorly 
conducting bone as opposed to the low resistance fluid compartments. Modeling of the current paths is necessary to understand what is activated [Schier et al., 2018].

Physically the simplest electrodes, but physiologically the most complex, are the large surface area electrodes on the mastoid delivering low current DC (usually $<5 \mathrm{~mA}$ ) or varying pulse rates for bipolar biphasic galvanic vestibular stimulation. These large electrodes deliver what is termed "surface galvanic stimulation" (GVS) but they indiscriminately activate both canals and otolithic afferents. There is a galvanic VEMP elicited by galvanic pulses to the mastoids [Rosengren et al., 2009], but because of the spread of galvanic stimulation, one cannot be definite about the extent to which that response is due to activation of otolithic afferents, since afferents from all sense organs will be activated.

Recent physiology has elaborated exactly how electrical stimulation of the vestibular labyrinth works - it activates both receptors and primary afferents [Gensberger et al., 2016; Dlugaiczyk et al., 2019]. It activates afferents from all vestibular sensory regions [Kim and Curthoys, 2004] and preferentially activates the irregular afferents of the transient system because of their lower average threshold than the regular afferents of the sustained system [Goldberg et al., 1984; Kim and Curthoys, 2004]. GVS stimulates all vestibular sense organs - simultaneously activating both canals and otoliths, and with, usually, complementary effects for the 2 labyrinths since the usual GVS stimulation protocol is bilateral bipolar mastoid stimulation with the anode on one mastoid and the cathode on the other. The result is that all the vestibular afferents in one labyrinth are activated and all the vestibular afferents in the opposing labyrinth are inhibited.

\section{Conclusion}

This paper has shown how the pioneering results from Uchino's lab showing commissural and cross-striolar inhibitory interaction in the otoliths (summarized in Uchino [2004] and Uchino and Kushiro [2011]) explain the otolithic response to linear acceleration, to unilateral and bilateral galvanic mastoid stimulation and also unilateral loss of otolithic maculae. Those results underpin the interpretation of clinical otolithic responses. They are also crucial in the next stage of the vestibular implant - the otolithic implant.

\section{Acknowledgment}

I am grateful to the Garnett Passe and Rodney Williams Memorial Foundation for their support of the Vestibular Research Laboratory.

\section{Statement of Ethics}

The author has no ethical conflicts to disclose.

\section{Disclosure Statement}

The author is an unpaid consultant to GN Otometrics, Taastrup, Denmark, but has received support from GN Otometrics for travel and attendance at conferences and workshops.

\section{Author Contributions}

I am solely responsible for all aspects of this paper.

\section{References}

Bergström B. Morphology of the vestibular nerve. II. The number of myelinated vestibular nerve fibers in man at various ages. Acta Otolaryngol. 1973 Aug-Sep;76(2):173-9.

Boutros PJ, Schoo D, Rahman M, Valentin NS, Chow M, Ayiotis A, et al. Continuous vestibular implant stimulation partially restores eyestabilizing reflexes. Manuscript submitted for publication 2019.

Burgess AM, Mezey LE, Manzari L, MacDougall HG, McGarvie LA, Curthoys IS. Effect of stimulus rise-time on the ocular vestibularevoked myogenic potential to bone-conducted vibration. Ear Hear. 2013 Nov-Dec;34(6): 799-805.
Chow M, Hageman K, Roberts D, Della Santina C. Temporal dynamics of eye movements elicited by combined otolith and semicircular canal stimulation. J Vestib Res. 2018;28:3-4.

Cohen B, Suzuki JI, Bender MB. Eye Movements from Semicircular Canal Nerve Stimulation in the Cat. Ann Otol Rhinol Laryngol. 1964 Mar;73(1):153-69.

Curthoys IS. Eye movements produced by utricular and saccular stimulation. Aviat Space Environ Med. 1987 Sep;58(9 Pt 2):A192-7.

Curthoys IS. A critical review of the neurophysiological evidence underlying clinical vestibular testing using sound, vibration and galvanic stimuli. Clin Neurophysiol. 2010 Feb; 121(2):132-44.
Curthoys IS, Burgess AM, Goonetilleke SC. Phase-locking of irregular guinea pig primary vestibular afferents to high frequency (> $250 \mathrm{~Hz}$ ) sound and vibration. Hear Res. 2019a Mar;373:59-70.

Curthoys IS, Grant JW, Burgess AM, Pastras CJ, Brown DJ, Manzari L. Otolithic Receptor Mechanisms for Vestibular-Evoked Myogenic Potentials: A Review. Front Neurol. 2018 May;9:366.

Curthoys IS, Grant JW, Pastras CJ, Brown DJ, Burgess AM, Brichta AM, et al. A review of mechanical and synaptic processes in otolith transduction of sound and vibration for clinical VEMP testing. J Neurophysiol. 2019b Jul; 122(1):259-76. 
Curthoys IS, Kim J, McPhedran SK, Camp AJ. Bone conducted vibration selectively activates irregular primary otolithic vestibular neurons in the guinea pig. Exp Brain Res. 2006 Nov; 175(2):256-67.

Curthoys IS, MacDougall HG, Vidal PP, de Waele C. Sustained and transient vestibular systems: a physiological basis for interpreting vestibular function. Front Neurol. 2017 Mar;8:117.

Curthoys IS, Markham CH. Convergence of labyrinthine influences on units in the vestibular nuclei of the cat. I. Natural stimulation. Brain Res. 1971 Dec;35(2):469-90.

Curthoys IS, Smith PF, Darlington CL. Postural compensation in the guinea pig following unilateral labyrinthectomy. Prog Brain Res. 1988;76:375-84.

Curthoys IS, Vulovic V, Burgess AM, Sokolic L, Goonetilleke SC. The response of guinea pig primary utricular and saccular irregular neurons to bone-conducted vibration (BCV) and air-conducted sound (ACS). Hear Res. 2016 Jan;331:131-43.

Curthoys IS, Vulovic V, Sokolic L, Pogson J, Burgess AM. Irregular primary otolith afferents from the guinea pig utricular and saccular maculae respond to both bone conducted vibration and to air conducted sound. Brain Res Bull. 2012 Oct;89(1-2):16-21.

Curthoys IS, Wearne SL, Dai M, Halmagyi GM, Holden JR. Linear acceleration modulates the nystagmus induced by angular acceleration stimulation of the horizontal canal. Ann N Y Acad Sci. 1992 May;656:716-24.

De Waele C, Graf W, Josset P, Vidal PP. A radiological analysis of the postural syndromes following hemilabyrinthectomy and selective canal and otolith lesions in the guinea pig. Exp Brain Res. 1989;77(1):166-82.

Dickman JD, Angelaki DE. Vestibular convergence patterns in vestibular nuclei neurons of alert primates. J Neurophysiol. 2002 Dec; 88(6):3518-33

Dlugaiczyk J, Gensberger KD, Straka H. Galvanic vestibular stimulation: from basic concepts to clinical applications. J Neurophysiol. 2019 Jun;121(6):2237-55.

Fernández C, Goldberg JM. Physiology of peripheral neurons innervating otolith organs of the squirrel monkey. III. Response dynamics. J Neurophysiol. 1976a Sep;39(5):996-1008.

Fernández C, Goldberg JM. Physiology of peripheral neurons innervating otolith organs of the squirrel monkey. I. Response to static tilts and to long-duration centrifugal force. J Neurophysiol. 1976b Sep;39(5):970-84.

Fernández C, Goldberg JM, Baird RA. The vestibular nerve of the chinchilla. III. Peripheral innervation patterns in the utricular macula. J Neurophysiol. 1990 Apr;63(4):767-80.

Flock A. Structure of the macula utriculi with special reference to directional interplay of sensory responses as revealed by morphological polarization. J Cell Biol. 1964 Aug;22(2):41331.
Fluur E, Mellström A. Utricular stimulation and oculomotor reactions. Laryngoscope. 1970a Nov;80(11):1701-12.

Fluur E, Mellström A. Saccular stimulation and oculomotor reactions. Laryngoscope. 1970b Nov;80(11):1713-21.

Gensberger KD, Kaufmann AK, Dietrich H, Branoner F, Banchi R, Chagnaud BP, et al. Galvanic Vestibular Stimulation: Cellular Substrates and Response Patterns of Neurons in the Vestibulo-Ocular Network. J Neurosci. 2016 Aug;36(35):9097-110.

Glueckert R, Johnson Chacko L, Schmidbauer D, Potrusil T, Pechriggl EJ, Hoermann R, et al. Visualization of the Membranous Labyrinth and Nerve Fiber Pathways in Human and Animal Inner Ears Using MicroCT Imaging. Front Neurosci. 2018 Jul;12:501.

Goldberg JM. Afferent diversity and the organization of central vestibular pathways. Exp Brain Res. 2000 Feb;130(3):277-97.

Goldberg JM. The Vestibular System: a sixth sense. New York: Oxford University Press; 2012. https://doi.org/10.1093/acprof:o so/9780195167085.001.0001.

Goldberg JM, Desmadryl G, Baird RA, Fernández C. The vestibular nerve of the chinchilla. IV. Discharge properties of utricular afferents. J Neurophysiol. 1990 Apr;63(4):781-90.

Goldberg JM, Fernández C. Conduction times and background discharge of vestibular afferents. Brain Res. 1977 Feb;122(3):545-50.

Goldberg JM, Smith CE, Fernández C. Relation between discharge regularity and responses to externally applied galvanic currents in vestibular nerve afferents of the squirrel monkey. J Neurophysiol. 1984 Jun;51(6):1236-56.

Goto F, Meng H, Bai R, Sato H, Imagawa M, Sasaki $\mathrm{M}$, et al. Eye movements evoked by the selective stimulation of the utricular nerve in cats. Auris Nasus Larynx. 2003 Dec;30(4): 341-8.

Goto F, Meng H, Bai R, Sato H, Imagawa M, Sasaki M, et al. Eye movements evoked by selective saccular nerve stimulation in cats. Auris Nasus Larynx. 2004 Sep;31(3):220-5.

Hageman KN, Chow MR, Roberts D, Della Santina CC. Binocular 3D otolith-ocular reflexes: responses of normal chinchillas to tilt and translation. Manuscript submitted for publication, 2019.

Halmagyi GM, Chen L, MacDougall HG, Weber KP, McGarvie LA, Curthoys IS. The video head impulse test. Front Neurol. 2017 Jun;8: 258.

Handler M, Schier PP, Fritscher KD, Raudaschl P, Johnson Chacko L, Glueckert R, et al. Modelbased Vestibular Afferent Stimulation: Modular Workflow for Analyzing Stimulation Scenarios in Patient Specific and Statistical Vestibular Anatomy. Front Neurosci. 2017 Dec;11:713.

Hara M, Kimura RS. Morphology of the membrana limitans. Ann Otol Rhinol Laryngol. 1993 Aug;102(8 Pt 1):625-30.
Hess BJ, Dieringer N. Spatial organization of linear vestibuloocular reflexes of the rat: responses during horizontal and vertical linear acceleration. J Neurophysiol. 1991 Dec;66(6):1805-18.

Iwasaki S, Smulders YE, Burgess AM, McGarvie LA, Macdougall HG, Halmagyi GM, et al. Ocular vestibular evoked myogenic potentials in response to bone-conducted vibration of the midline forehead at Fz. A new indicator of unilateral otolithic loss. Audiol Neurotol. 2008;13(6):396-404.

Kim J. Head movements suggest canal and otolith projections are activated during galvanic vestibular stimulation. Neuroscience. 2013 Dec; 253:416-25.

Kim J, Curthoys IS. Responses of primary vestibular neurons to galvanic vestibular stimulation (GVS) in the anaesthetised guinea pig. Brain Res Bull. 2004 Sep;64(3):265-71.

Lansberg MP, Guedry FE, Graybiel A. Effect of changing resultant linear acceleration relative to subject on nystagmus generated by angular acceleration. Aerosp Med. 1965;36:456-60.

Lee WS, Suárez C, Honrubia V, Gómez J. Morphological aspects of the human vestibular nerve. Laryngoscope. 1990 Jul;100(7):756-64.

Lindeman HH. Studies on the morphology of the sensory regions of the vestibular apparatus with 45 figures. Ergeb Anat Entwicklungsgesch. 1969;42(1):1-113.

Lopez I, Ishiyama G, Tang Y, Frank M, Baloh RW, Ishiyama A. Estimation of the number of nerve fibers in the human vestibular endorgans using unbiased stereology and immunohistochemistry. J Neurosci Methods. 2005 Jun;145(1-2):37-46.

MacDougall HG, Brizuela AE, Curthoys IS, Halmagyi GM. Three-dimensional eye-movement responses to surface galvanic vestibular stimulation in normal subjects and in patients: a comparison. Ann N Y Acad Sci. 2002 Apr;956(1):546-50.

Maklad A, Kamel S, Wong E, Fritzsch B. Development and organization of polarity-specific segregation of primary vestibular afferent fibers in mice. Cell Tissue Res. 2010 May; 340(2):303-21.

Markham CH, Yagi T, Curthoys IS. The contribution of the contralateral labyrinth to second order vestibular neuronal activity in the cat. Brain Res. 1977 Dec;138(1):99-109.

Mukherjee P, Cheng K, Curthoys I. Three-dimensional study of vestibular anatomy as it relates to the stapes footplate and its clinical implications: an augmented reality development. J Laryngol Otol. 2019 Mar;133(3):187-91.

Mukherjee P, Uzun-Coruhlu H, Curthoys IS, Jones AS, Bradshaw AP, Pohl DV. Three-dimensional analysis of the vestibular end organs in relation to the stapes footplate and piston placement. Otol Neurotol. 2011 Apr; 32(3):367-72.

Otero-Millan J, Treviño C, Winnick A, Zee DS, Carey JP, Kheradmand A. The video ocular counter-roll (vOCR): a clinical test to detect loss of otolith-ocular function. Acta Otolaryngol. 2017 Jun;137(6):593-7. 
Parkes WJ, Gnanasegaram JJ, Cushing SL, McKnight CL, Papsin BC, Gordon KA. Vestibular evoked myogenic potential testing as an objective measure of vestibular stimulation with cochlear implants. Laryngoscope. 2017 Feb; 127(2):E75-81.

Pastras C, Curthoys IS, Brown DJ. Dynamic Response and Sensitivity of the Utricular Macula, Measured in vivo Using Laser Doppler Vibrometry in Guinea Pigs. PS547. Abstr Assoc Res Otolaryngol. 2018;41:342.

Popper AN, Fay RR. Rethinking sound detection by fishes. Hear Res. 2011 Mar;273(1-2):2536.

Precht W, Shimazu H. Functional connections of tonic and kinetic vestibular neurons with primary vestibular afferents. J Neurophysiol. 1965 Nov;28(6):1014-28.

Rosengren SM, Colebatch JG. The Contributions of Vestibular Evoked Myogenic Potentials and Acoustic Vestibular Stimulation to Our Understanding of the Vestibular System. Front Neurol. 2018 Jun;9:481.

Rosengren SM, Jombik P, Halmagyi GM, Colebatch JG. Galvanic ocular vestibular evoked myogenic potentials provide new insight into vestibulo-ocular reflexes and unilateral vestibular loss. Clin Neurophysiol. 2009 Mar; 120(3):569-80.
Schier P, Handler M, Johnson Chacko L, SchrottFischer A, Fritscher K, Saba R, et al. ModelBased Vestibular Afferent Stimulation: Evaluating Selective Electrode Locations and Stimulation Waveform Shapes. Front Neurosci. 2018 Aug; 12:588.

Smith PF, Curthoys IS. Mechanisms of recovery following unilateral labyrinthectomy: a review. Brain Res Brain Res Rev. 1989 Apr-Jun; 14(2):155-80

Suzuki JI, Tokumasu K, Goto K. Eye movements from single utricular nerve stimulation in the cat. Acta Otolaryngol. 1969 Oct;68(4):35062.

Uchino Y. Role of cross-striolar and commissural inhibition in the vestibulocollic reflex. In: Mori S, Stuart DG, Wiesendanger M, editors. Brain Mechanisms for the Integration of Posture and Movement. Progress in Brain Research. 2004. Vol 143. pp. 403-9.

Uchino Y, Kushiro K. Differences between otolith- and semicircular canal-activated neural circuitry in the vestibular system. Neurosci Res. 2011 Dec;71(4):315-27.
Uzun-Coruhlu H, Curthoys IS, Jones AS. Attachment of the utricular and saccular maculae to the temporal bone. Hear Res. 2007 Nov; 233(1-2):77-85.

Watson SR, Brizuela AE, Curthoys IS, Colebatch JG, MacDougall HG, Halmagyi GM. Maintained ocular torsion produced by bilateral and unilateral galvanic (DC) vestibular stimulation in humans. Exp Brain Res. 1998 Oct; 122(4):453-8.

Yagi T, Simpson NE, Markham CH. The relationship of conduction velocity to other physiological properties of the cat's horizontal canal neurons. Exp Brain Res. 1977 Dec;30(4):587600.

Zeddies DG, Fay RR, Gray MD, Alderks PW, Acob A, Sisneros JA. Local acoustic particle motion guides sound-source localization behavior in the plainfin midshipman fish, Porichthys notatus. J Exp Biol. 2012 Jan; 215(Pt 1):152-60.

Zhu H, Tang X, Wei W, Mustain W, Xu Y, Zhou W. Click-evoked responses in vestibular afferents in rats. J Neurophysiol. 2011 Aug; 106(2):754-63. 